\title{
The influence of anesthesia with isoflurane on the pulmonary and aortic blood flow of Racing Pigeons (Columba livia f. domestica) measured by pulsed wave Doppler echocardiography
}

\author{
Marko Legler*, Lajos Koy, Norbert Kummerfeld and Michael Fehr \\ Clinic for Small Mammals, Reptiles and Birds, University of Veterinary Medicine Hannover, Foundation, D-30559 \\ Hannover, Germany
}

\begin{abstract}
Doppler echocardiographic examinations are an important technique for evaluating the blood flow also in avian cardiology. The influence of anesthesia on the blood flow in the heart is in detail unknown for the most avian species. The present study investigated the influence of an isoflurane anesthesia on the systolic blood flow of the aorta and the pulmonary artery in the area of the heart valves examined by pulsed wave Doppler sonography in Racing Pigeons (Columba livia f. domestica, $n=43$ ). Measurements were taken in conscious and anaesthetized birds in the left (aorta) and right (pulmonary artery) parasternal longitudinal horizontal heart view. The results demonstrated a significant decrease in heart rate and systolic peak flow velocities as well as prolonged ejection times during anesthesia. A positive correlation of systolic peak flow velocity and heart rate could be demonstrated, especially for the pulmonary artery in conscious pigeons. The aortic systolic peak flow velocity and heart rate showed a significantly negative correlation in anaesthetized pigeons. These correlations should be borne in mind in the echocardiographic examination, especially of conscious birds. A higher incidence of second degree atrioventricular block (30.23\%) was induced by anesthesia in the Racing Pigeons. These results of the present study indicate the necessity for establishing normal heart values in conscious and anaesthetized individuals.
\end{abstract}

Keywords: Aorta, Birds, Blood flow velocity, Pulmonary artery, Sonography.

\section{Introduction}

The examination of bird species under anesthesia with isoflurane is a common practice in the avian medicine. The drug isoflurane allows an easily controllable and safe anesthesia in birds (Korbel et al., 1993; Korbel, 1998; Botman et al., 2016). The majority of avian echocardiography studies have been conducted under isoflurane anesthesia (Boskovic et al., 1999; Pees, 2001; Straub et al., 2001; Pees et al., 2004). However, in ill birds with a highly disturbed general condition, a general anesthetic is not recommended. Little is known about the influence of the anesthetic isoflurane on the Doppler-derived blood flow velocities, flow pattern, myocardial, or heart valve functions in the avian species. In small animal medicine, the influence of anesthesia on cardiac parameters is well described (Fox et al., 1985; Yang et al., 1999; Chaves et al., 2001; Kiatchoosakun et al., 2001; Roth et al., 2002; Plante et al., 2006; Stein et al., 2007; Stypmann et al., 2007). Especially, the decrease in the diastolic and systolic blood peak flow velocities measured in Doppler echocardiography is well-known in the mammals (Stypmann et al., 2007). Straub et al. (2003) showed an initial overview of the influence of anesthesia with isoflurane on the results of Doppler-derived blood flow measurements in Common Buzzards (Buteo buteo), a significant decrease in heart rate, the aortic flow velocity, and the diastolic filling velocities.

The aim of the present study was to examine the influence of isoflurane anesthesia on the systolic blood flow of the Racing Pigeon heart measured by pulsed wave (PW) Doppler sonography.

\section{Materials and Methods}

The study was conducted in accordance with the German animal welfare regulations and with the permission of the German authorities (reference number: 33.1242502-04-15/1864).

\section{Experimental animals}

Racing Pigeons (Columba livia f. dom.; $n=43$ ) of both sexes (male: $n=16$; female: $n=27$ ) were used for the investigations. The pigeons were $2.30 \pm \mathrm{SD}$ 1.69 (range: $0.5-8$ ) yr old and had a weight of 468.16 \pm SD 51.64 (range: $352-577$ ) g body mass and were trained for racing. The sternal length of the pigeons measured from the visible sternocoracoid joint to the end of the sternum in laterolateral radiographic images was 73.4 millimeter $(\mathrm{mm} \pm \mathrm{SD} 3.1 \mathrm{~mm}$ (range: $63.2-81.0 \mathrm{~mm}$ ). The pigeons were housed in indoor aviaries, being offered a commercial pigeon seed mix and fresh drinking water ad libitum and were routinely vaccinated by the owner for pigeon paramyxovirus 
1 and salmonellosis. All pigeons showed a normal feeding and drinking behavior. Prior to the ultrasound examinations, the pigeons were acclimatized for $2 \mathrm{wk}$ in the new aviaries. In this time, a bacteriological and parasitological testing of a composite fecal sample of the pigeons for salmonella and endoparasites of the intestine were negative. A microscopic examination of fresh crop samples revealed in some pigeons a low grade infestation with Trichomonas gallinae and all pigeons were treated with $10 \mathrm{mg}$ Carnidazol (Spatrix ${ }^{\circledR}$, Elanco Deutschland $\mathrm{GmbH}$ ). The pigeons were declared healthy by clinical, hematological, and radiological examinations. The maximum width of the cardiac silhouette of the pigeons measured in the ventrodorsal radiograph were $58.8 \% \pm 3.3(50.3 \%-65.1 \%)$ of the maximum width of the thorax and comparable to results of healthy birds in the literature (Pees et al., 2006). The hematocrit $(44.9 \% \pm 1.8 ; 42.0 \%-49.0 \%)$ and the buffy coat $(<1 \%)$ of the pigeons were in the reference values of healthy and normal hydrated pigeons (Fudge, 2000). Egg-laying pigeons were excluded from sonographic examinations.

\section{Doppler-sonographic examination}

Echocardiographic images were acquired by using a 10 $\mathrm{MHz}$ linear-array transducer (B Mode $4.5-11.5 \mathrm{MHz}$ ) with a digital ultrasound system (Vivid 7 Dimension BT08, GE Medical Systems) in combination with an electrocardiogram according to Einthoven (Lumeij and Stokhof, 1985; Lumeij and Ritchie, 1994). The pigeons were fixed in a semi-upright position for the sonographic examination of the heart from the left and right parasternal approach. Depending on the individual bird, the left and right fenestra or the space behind the last rib through the liver to the heart were chosen as acoustic windows. The 2-D echocardiographic images were named and oriented in accordance with Riedel (1995), Schulz (1995), and Pees et al. (2006). The left parasternal longitudinal horizontal view (four chamberview) was used to measure the velocity of the aorta (AO) and the right parasternal longitudinal horizontal view was chosen to measure the velocity of the pulmonary artery (PA). The blood flow velocities were estimated at the level of the heart valves by PW Doppler Sonography. The sample volume was $1.5 \mathrm{~mm}$. A wall filter setting of $3.4 \mathrm{~cm} / \mathrm{sec}$ was chosen. Sonographic images were used in the evaluations that were generated with a setting of more than 200 frames/sec. The angle correction cursor was used for every measurement, aligning it as parallel as possible to the direction of blood flow (Color flow Doppler) or the visible artery wall.

In each Racing Pigeon, the echocardiographic examination was performed once in conscious birds and once under general anesthesia with isoflurane (Isofluran $\mathrm{CP}^{\circledR}, \mathrm{CP}$ Pharma GmbH, Burgdorf, Germany) at a minimum interval of $2 \mathrm{~d}$. Anesthesia was induced with $4 \%$ isoflurane in $1 \mathrm{~L} / \mathrm{min}$ oxygen and maintained with $1 \%$ to $3 \%$ isoflurane in $1 \mathrm{~L} / \mathrm{min}$ oxygen with an anesthetic mask and spontaneous breath. The depth of anesthesia was calculated by toe pinch and wing twitch reflexes. The echocardiographic examination was performed during the stage of surgical anesthesia. Measurements of the flow pattern were taken over six sequential individual heart beats in each PW Doppler image and the mean was used for the further evaluations. In some pigeons, more than one PW Doppler images per location (maximum three images) were analyzed depending on the heart rate. In these cases also, the mean of the different measurements of one examined pigeons was used in the statistical tests. All measurements were performed with calipers on the frozen screen images using the on-board ultrasound system computer. The systolic peak flow velocities in meter per second $(\mathrm{m} / \mathrm{s})$ were determined at the time of maximum systolic blood flow velocity. Flow time (ejection time) was calculated from the onset of flow to the termination of flow in milliseconds (ms). To compare and quantify the effect of anesthesia on PW Doppler blood flow spectra of the aorta and pulmonary artery, the acceleration time (AT) in ms from the onset of ejection to the peak flow velocity and the deceleration time (DT) in ms from the peak flow velocity to the end of ejection were measured.

\section{Statistical analysis}

Statistical tests were performed using SPSS ${ }^{\circledR}$ Statistics 24. Mean, median, standard deviation (SD), and range (Xmin to Xmax) were calculated for the different parameters of the flow pattern of AO and PA. The Kolmogorov-Smirnov test was used to test for normal distribution of the measured values. According to these results, the Student's $t$-test for matched pairs or the Wilcoxon signed-rank test as well as the Student's unpaired $t$-test or the Mann-Whitney $U$-test was chosen for the evaluations. The Spearman's rank correlation coefficient was used to visualize the influence of the heart rate on parameters of aortic and pulmonary blood flow pattern of conscious and anaesthetized pigeons. A significance level of $p \leq 0.05$ was chosen.

\section{Results}

Adequate measurements of the systolic blood flow pattern in the $\mathrm{AO}$ were possible in 43 Racing Pigeons and of the PA in 40 pigeons. In some cases, visible diastolic blood flow in the Doppler images showed the measurement in the right ventricular outflow tract. In some pigeons, more than one PW Doppler image depending on the fast changing heart rate were analyzed; in total, 63 images of $\mathrm{AO}$ and 60 images of $\mathrm{PA}$ in conscious and 45 images of $\mathrm{AO}$ and 46 of PA in anaesthetized pigeons.

The heart rate was significantly lower in the anaesthetized pigeons (151.76 \pm SD 38.38) as compared with conscious (208.67 \pm SD 44.81) pigeons (Fig. 1). In 3 out of 43 conscious pigeons $(6.98 \%)$, we found a second-degree atrioventricular block. The anesthesia with isoflurane led to a development of a second-degree atrioventricular block in 13 out of 43 (30.23) pigeons. 


\section{Peak flow velocities}

Statistically significant differences between awake and anaesthetized Racing Pigeons were detected in pulmonary and aortic systolic blood flow velocities. An overview of the detected results in all examined images is shown in Tables $1-4$. The aortic blood flow changed from $1.18 \mathrm{~m} / \mathrm{s} \pm \mathrm{SD} 0.15$ in awake birds to $0.95 \mathrm{~m} / \mathrm{s} \pm \mathrm{SD} 0.15$ ( $p<0.001$; Student's paired $t$-test; Fig. 2) and the blood flow velocity of the PA decreased from $1.08 \pm \mathrm{SD} 0.20$ to $0.64 \pm \mathrm{SD} 0.11(p<$ 0.001 , Student's paired $t$-test; Fig. 3 ) in anaesthetized pigeons. The mean blood flow velocity of the PA (mean decrease $0.44 \pm$ SD 0.20 ) was more affected by anesthesia than the aortic blood flow (mean decrease $0.24 \pm$ SD 0.18).

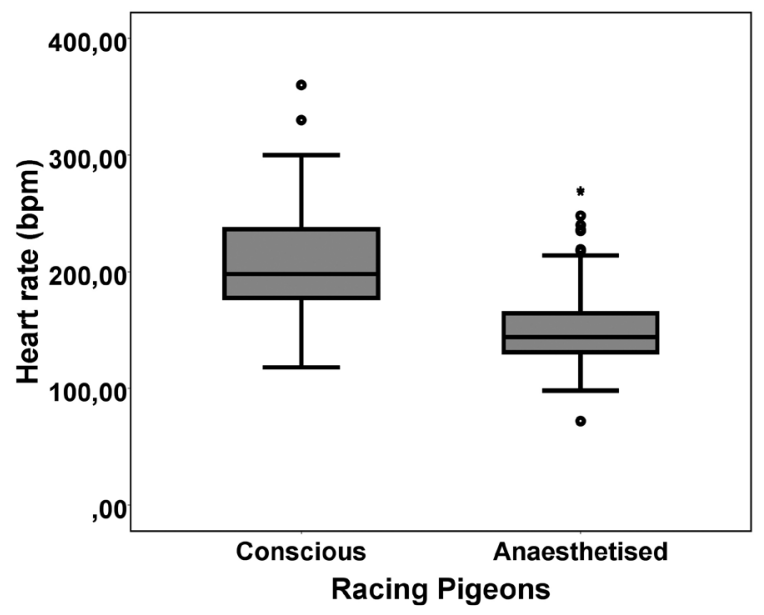

Fig. 1. Comparison of the heart rate of conscious and anaesthetized Racing Pigeons (Columba livia f. domestica). The box plot shows median (horizontal line in centre), the 25 th percentile (box border at bottom), and the 75 th percentile (box border at top). The upper and lower ends of the whisker show the maximum and minimum values. The single data points are outliers.

\section{Aortic and pulmonary flow pattern}

The detailed comparison between the aortic and pulmonary valve flow of the pigeons revealed the known different flow spectra of the $\mathrm{AO}$ and PA in the range of the examined heart rates up to $360 \mathrm{bpm}$, with significant differences between ejection time, acceleration, and deceleration time between aortic and pulmonary blood flow ( $p \leq 0.05$; Mann-Whitney $U$-test; Tables 1-4). Pulmonary flow displayed a gradual acceleration, reaching a rounded peak followed by a gradual deceleration, with a significantly longer AT and shorter DT in conscious birds ( $p \leq 0.001$; Mann-Whitney $U$-test). In contrast, the aortic flow accelerated rapidly to a sharp peak in early systole and then decelerates at a slower rate. There was a significant difference between pulmonary and the slightly shorter aortic ejection times $(p<0.001$, Mann-Whitney $U$-test $)$.

The anesthesia with isoflurane also had a significant influence on the flow pattern of AO and PA (Tables 2 and 4). The main observations in anaesthetized birds were prolonged ejection times (AO: from $67.03 \mathrm{~ms} \pm$ SD 8.65 to $90.26 \mathrm{~ms} \pm \mathrm{SD} 14.80, p<0.001$, Wilcoxon signed-rank test; PA: from $71.90 \mathrm{~ms} \pm \mathrm{SD} 8.27$ to $103.02 \mathrm{~ms} \pm \mathrm{SD} 13.87, p<0.001$, Wilcoxon signedrank test) as well as acceleration $(p<0.001$; Wilcoxon signed-rank test) and deceleration times $(p<0.001$; Wilcoxon signed-rank test) in the aortic and pulmonary blood flows. In anesthesia, the mean aortic ejection time was again significantly shorter than the blood flow time in the PA $(p<0.001$; Mann-Whitney $U$-test $)$. The anesthesia also had an influence on blood flow spectra. In anesthesia, the pulmonary blood flow reached faster peak flow velocities compared with awake pigeons (AT $=\mathrm{DT} ; p=0.829$, Wilcoxon signed-rank test). The aortic blood flow spectrum was not affected by anesthesia.

Influence of heart rate on aortic and pulmonary blood flow pattern

\section{Conscious pigeons}

The influence of the heart rate on the peak flow velocity of the aortic blood flow in awake pigeons was not

Table 1. Selected Doppler-derived parameter of aortic blood flow of awake Racing Pigeons (Columba livia f. domestica; $n=43$ ).

\begin{tabular}{ccc}
\hline Parameter & Mean \pm SD & $\begin{array}{c}\text { Median } \\
\text { (Xmin- Xmax })\end{array}$ \\
\hline $\mathrm{Vel}_{\mathrm{AO}}(\mathrm{m} / \mathrm{s})$ & $1.19 \pm 0.15$ & $1.19(0.79-1.55)$ \\
\hline $\mathrm{AC}_{\mathrm{AO}}($ degree $)$ & $10.75 \pm 6.93$ & $12.00(0.00-32.00)$ \\
\hline $\mathrm{HR}_{\mathrm{AO}}(\mathrm{bpm})$ & $209.76 \pm 43.96$ & $202.00(118-330)$ \\
\hline $\mathrm{ET}_{\mathrm{AO}}(\mathrm{ms})$ & $67.03 \pm 8.65$ & $65.31(56.31-110.90)$ \\
$\mathrm{AT}_{\mathrm{AO}}(\mathrm{ms})$ & $18.91 \pm 5.25$ & $17.87(7.33-38.19)$ \\
\hline $\mathrm{DT}_{\mathrm{AO}}(\mathrm{ms})$ & $48.27 \pm 6.21$ & $47.44(38.51-72.71)$ \\
\hline
\end{tabular}

$\mathrm{Vel}_{\mathrm{AO}}$ : peak flow velocity of aortic blood flow; $\mathrm{AC}_{\mathrm{AO}}$ : angle correction in echocardiographic measurement; $\mathrm{HR}_{\mathrm{AO}}$ : heart rate during measurements; $\mathrm{ET}_{\mathrm{AO}}$ : ejection time; $\mathrm{AT}_{\mathrm{AO}}$ : acceleration time of aortic blood flow; $\mathrm{DC}_{\mathrm{AO}}$ : deceleration time of aortic blood flow; SD: standard deviation. 
Table 2. Selected Doppler-derived parameter of aortic blood flow of anaesthetized Racing Pigeons with isoflurane (Columba livia f. domestica; $n=43$ ).

\begin{tabular}{ccc}
\hline Parameter & Mean \pm SD & $\begin{array}{c}\text { Median } \\
\text { (Xmin-Xmax) }\end{array}$ \\
\hline $\mathrm{Vel}_{\mathrm{AO}}(\mathrm{m} / \mathrm{s})$ & $0.95 \pm 0.15$ & $0.94(0.60-1.22)$ \\
$\mathrm{AC}_{\mathrm{AO}}($ degree $)$ & $10.29 \pm 8.23$ & $9.00(0.00-38.00)$ \\
\hline $\mathrm{HR}_{\mathrm{AO}}(\mathrm{bpm})$ & $154.64 \pm 45.15$ & $144.00(72-270)$ \\
$\mathrm{ET}_{\mathrm{AO}}(\mathrm{ms})$ & $90.26 \pm 14.80$ & $88.72(62.23-137.56)$ \\
$\mathrm{AT}_{\mathrm{AO}}(\mathrm{ms})$ & $25.80 \pm 5.11$ & $24.96(15.71-38.02)$ \\
$\mathrm{DT}_{\mathrm{AO}}(\mathrm{ms})$ & $64.54 \pm 12.79$ & $64.69(37.58-102.59)$ \\
\hline
\end{tabular}

$\mathrm{Vel}_{\mathrm{AO}}$ : peak flow velocity of aortic blood flow; $\mathrm{AC}_{\mathrm{AO}}$ : angle correction in echocardiographic measurement; $\mathrm{HR}_{\mathrm{AO}}$ : heart rate during measurements; $\mathrm{ET}_{\mathrm{AO}}$ : ejection time; $\mathrm{AT}_{\mathrm{AO}}$ : acceleration time of aortic blood flow; $\mathrm{DC}_{\mathrm{AO}}$ : deceleration time of aortic blood flow; SD: standard deviation.

Table 3. Selected Doppler-derived parameter of pulmonary blood flow of awake Racing Pigeons (Columba livia f. domestica; $n=40$ ).

\begin{tabular}{ccc}
\hline Parameter & Mean \pm SD & $\begin{array}{c}\text { Median } \\
(\text { Xmin-Xmax })\end{array}$ \\
\hline $\operatorname{Vel}_{\mathrm{PA}}(\mathrm{m} / \mathrm{s})$ & $1.08 \pm 0.20$ & $1.06(0.70-1.59)$ \\
$\mathrm{AC}_{\mathrm{PA}}($ degree $)$ & $7.28 \pm 8.90$ & $6.50(0.00-35.00)$ \\
\hline $\mathrm{HR}_{\mathrm{PA}}(\mathrm{bpm})$ & $207.53 \pm 46.04$ & $195.50(136-360)$ \\
$\mathrm{ET}_{\mathrm{PA}}(\mathrm{ms})$ & $71.90 \pm 8.27$ & $71.47(53.61-92.42)$ \\
$\mathrm{AT}_{\mathrm{PA}}(\mathrm{ms})$ & $38.08 \pm 5.15$ & $38.15(29.57-56.07)$ \\
$\mathrm{DT}_{\mathrm{PA}}(\mathrm{ms})$ & $33.82 \pm 7.49$ & $34.20(12.06-52.99)$ \\
\hline
\end{tabular}

$\mathrm{Vel}_{\mathrm{PA}}$ : peak flow velocity of pulmonary blood flow; $\mathrm{AC}_{\mathrm{PA}}$ : angle correction in echocardiographic measurement; $\mathrm{HR}_{\mathrm{PA}}$ : heart rate during measurements; $\mathrm{ET}_{\mathrm{PA}}$ : ejection time; $\mathrm{AT}_{\mathrm{PA}}:$ acceleration time of pulmonary blood flow; $\mathrm{DC}_{\mathrm{PA}}$ : deceleration time of pulmonary blood flow; SD: standard deviation.

Table 4. Selected Doppler-derived parameter of pulmonary blood flow of anaesthetized Racing Pigeons with isoflurane (Columba livia $\mathrm{f}$. domestica; $\mathrm{n}=40$ ).

\begin{tabular}{ccc}
\hline Parameter & Mean \pm SD & Median $($ Xmin-Xmax) \\
\hline $\operatorname{Vel}_{\mathrm{PA}}(\mathrm{m} / \mathrm{s})$ & $0.64 \pm 0.11$ & $0.64(0.40-0.88)$ \\
\hline $\mathrm{AC}_{\mathrm{PA}}($ degree$)$ & $10.70 \pm 11.93$ & $8.00(0.00-41.00)$ \\
$\mathrm{HR}_{\mathrm{PA}}(\mathrm{bpm})$ & $148.94 \pm 30.61$ & $149.00(98-248)$ \\
$\mathrm{ET}_{\mathrm{PA}}(\mathrm{ms})$ & $103.02 \pm 13.88$ & $101.99(78.25-146.64)$ \\
$\mathrm{AT}_{\mathrm{PA}}(\mathrm{ms})$ & $51.32 \pm 7.05$ & $51.14(30.31-65.31)$ \\
\hline $\mathrm{DT}_{\mathrm{PA}}(\mathrm{ms})$ & $51.73 \pm 11.49$ & $52.22(31.79-81.33)$ \\
\hline
\end{tabular}

$\mathrm{Vel}_{\mathrm{PA}}$ : peak flow velocity of pulmonary blood flow; $\mathrm{AC}_{\mathrm{PA}}$ : angle correction in echocardiographic measurement; $\mathrm{HR}_{\mathrm{PA}}$ : heart rate during measurements; $\mathrm{ET}_{\mathrm{PA}}$ : ejection time; $\mathrm{AT}_{\mathrm{PA}}$ : acceleration time of pulmonary blood flow; $\mathrm{DC}_{\mathrm{PA}}$ : deceleration time of pulmonary blood flow; $\mathrm{SD}$ : standard deviation.

significant $(p=0.162)$. Thus, the results indicated that an increased heart rate in the range of 118 to $330 \mathrm{bpm}$ led only to a very low increase in the aortic velocity (Spearman's correlation coefficient $r=0.179$, very low correlation; Fig. 4). The influence of the heart rate on the peak flow velocity of the pulmonary artery in conscious pigeons was significant $(p \leq 0.001)$, an increasing heart rate (136-360 bpm) led to an increase in the pulmonary velocity (Spearman's correlation coefficient $r=0.512$, middle correlation; Fig. 6). The 
influence of the heart rate on the ejection time of the $\mathrm{AO}$ and PA was also significant $(p \leq 0.001$; heart rates: 118-360 bpm; Spearman's correlation coefficient: AO: $r=-0.401$, low correlation; PA: $r=-0.645$, middle correlation).

\section{Anesthetized pigeons}

Anesthesia with isoflurane had a significant influence on the correlation of heart rate and the systolic blood flow pattern. Increasing heart rates under anesthesia were negatively correlated with decreasing peak flow velocities of the AO ( $p=0.007$; heart rate: $72-270 \mathrm{bpm}$; Spearman's correlation coefficient $r=-0.394$, low correlation). In contrast, the influence of the heart rate on the peak flow velocity of the PA was not significant ( $p=0.391$; heart rate: 98-248 bpm; Spearman's correlation coefficient $r=0.129$, very low correlation). The influence of the heart rate on the ejection time of the AO and the PA in anesthesia was also significant ( $p \leq 0.001$; Spearman's correlation coefficient AO: $r=-0.534$, middle correlation; PA: $r=-0,481$, low correlation).

Influence of sex, weight, and age on aortic and pulmonary blood flow pattern

There were no significant differences between female and male pigeons in the aortic $(p>0.5)$ and pulmonary $(p>0.5)$ peak flow velocities or in the systolic flow time $(p>0.35$; Mann-Whitney $U$-test $)$.

The age in the range of 0.5 to $8 \mathrm{yr}$ have no influence on the systolic blood flow pattern and velocities $(p>$ $0.5)$. There is a positive correlation of the body mass and sternal length $(p \leq 0.006$; Spearman's correlation coefficient $r=0.38-0.50$; low-to-middle correlation)

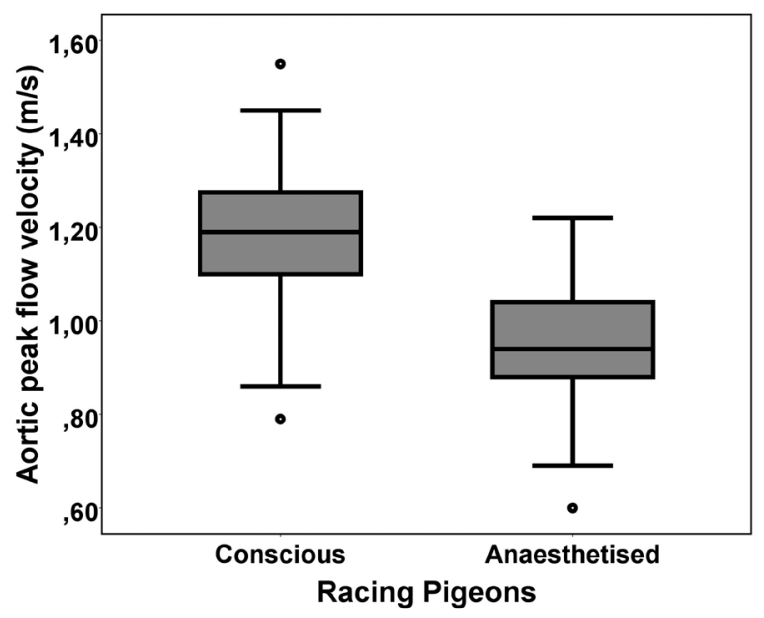

Fig. 2. Comparison of Doppler-derived systolic aortic peak flow velocities in valvular region of conscious and anaesthetized Racing Pigeons (Columba livia f. domestica). The box plot shows median (horizontal line in centre), the 25 th percentile (box border at bottom), and the 75 th percentile (box border at top). The upper and lower ends of the whisker show the maximum and minimum values. The single data points are outliers. and the acceleration time of the pulmonary blood flow pattern with and without anesthesia. These correlations could not be demonstrated for the aortic flow pattern. The body mass and sternal length have no influence on aortic and pulmonary blood flow velocities $(p \geq 0.12)$ as well as on the systolic blood flow time $(p>0.05)$.

\section{Discussion}

Isoflurane anesthesia had a significant influence on PW-Doppler derived systolic blood flow velocities and flow pattern in healthy Racing Pigeons, as was suspected from the data of other animals from the literature, for example, horses, dogs, rabbits, mice or humans (Murray et al., 1987; Kawasaki et al., 1994; Marano et al., 1997; Yamanaka et al., 2001; Roth et al., 2002; Vastenberg et al., 2004; Strypmann et al., 2007; Sousa et al., 2008), and birds (Straub et al., 2003). Especially, the influence on the heart rate is well described and could also be found in a study on the Common Buzzard (Buteo buteo; Straub et al., 2003) or other birds (Boltman et al., 2016). The heart rates in the conscious pigeons in our study should be interpreted as values at rest (Rüther, 1998). The birds were trained and accustomed to handling. The high SD reported for the heart rates under anesthesia in our study was attributed to pigeons with very low and with high baseline heart rates. Comparable data were observed in dogs under anesthesia with unknown cause (Sousa et al., 2008).

The PW-Doppler derived aortic and pulmonary systolic blood flow velocities were significantly reduced in our study during isoflurane anesthesia in pigeons. These results are also described in mammals, for example,

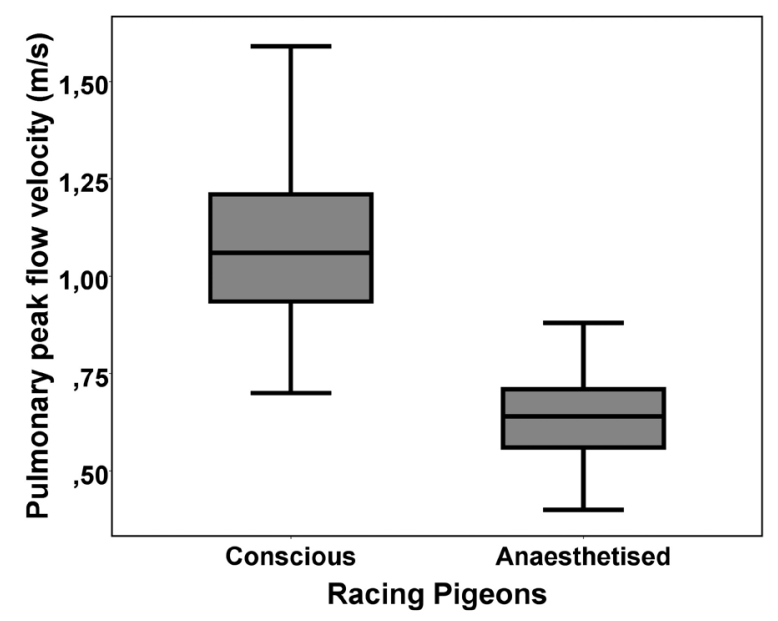

Fig. 3. Comparison of Doppler-derived systolic pulmonary peak flow velocities in valvular region of conscious and anaesthetized Racing Pigeons (Columba livia f. domestica). The box plot shows median (horizontal line in centre), the 25 th percentile (box border at bottom), and the 75 th percentile (box border at top). The upper and lower ends of the whisker show the maximum and minimum values. The single data points are outliers. 


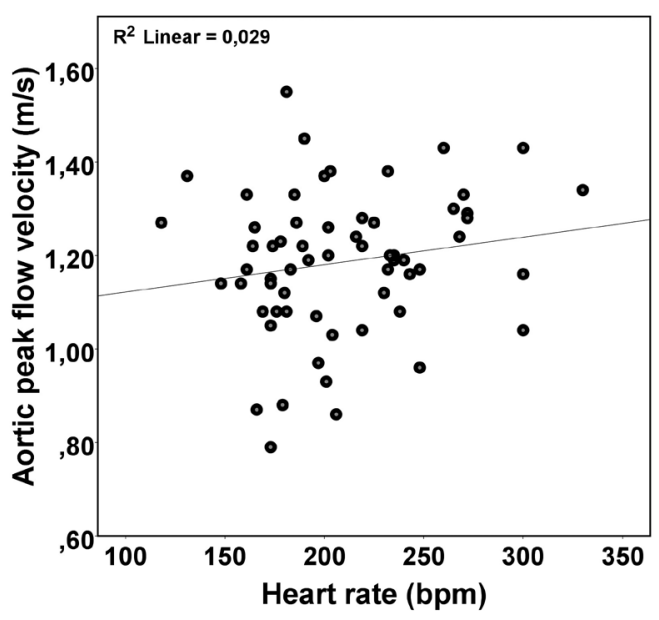

Fig. 4. Scatter diagram for the influence of the heart rate on aortic peak flow velocity in conscious Racing Pigeons (Columba livia f. domestica). Each point represents the peak flow velocities depending on the heart rate. The solid line estimates the average peak flow velocity at each heart rate.

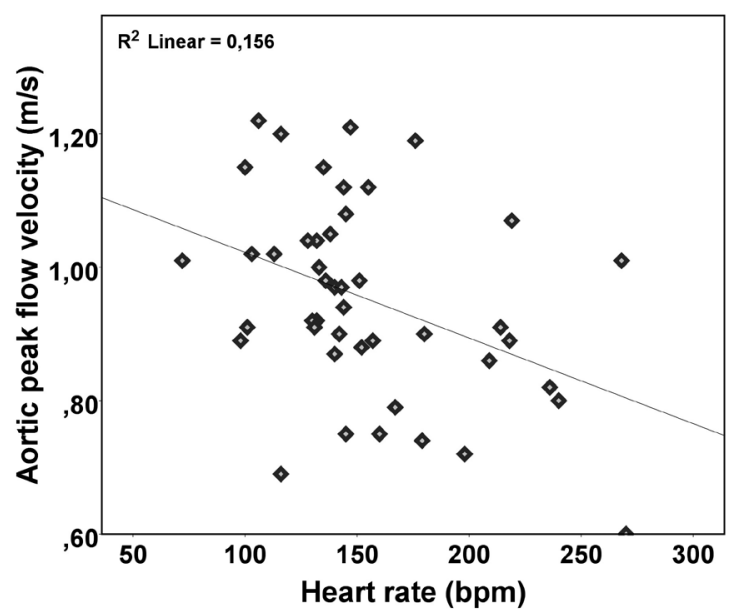

Fig. 5. Scatter diagram for the influence of the heart rate on aortic peak flow velocity in anaesthetized Racing Pigeons with isoflurane (Columba livia $\mathrm{f}$. domestica). Each point represents the peak flow velocities depending on the heart rate. The solid line estimates the average peak flow velocity at each heart rate.

Stypmann et al. (2007) or Sousa et al. (2008), and birds (Pees, 2001; Straub et al., 2003). Peak flow velocities are sensitive indexes of myocardial contractility (Sousa et al., 2008). Different studies show that isoflurane depresses myocardial contractility and arterial elastance in mammals (Kawasaki et al., 1994). Thus, anesthesia with isoflurane results in arterial blood pressure, cardiac output, and stroke volume decrease also in pigeons (Klide, 1976; Steffey and Howland, 1978; Eger, 1984; Pagel et al., 1991; Deryck et al., 1996; Botman et al., 2016). The detected aortic blood flow velocities in anaesthetized Racing Pigeons in our investigations are

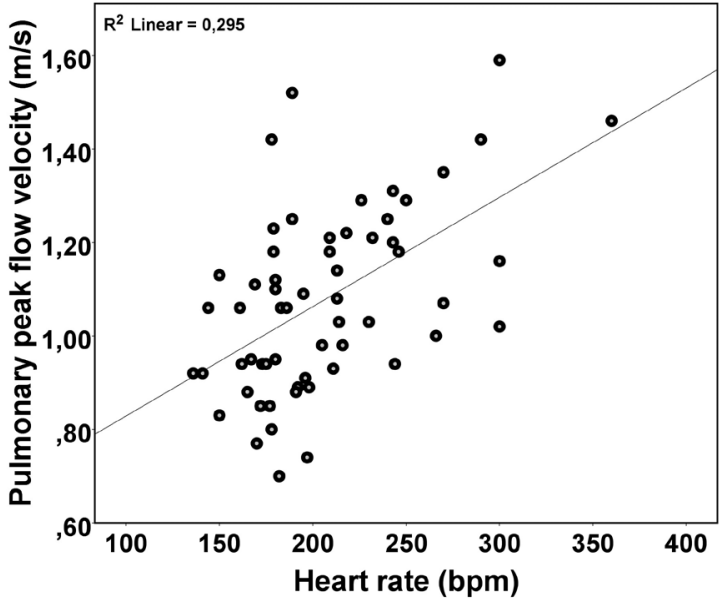

Fig. 6. Scatter diagram for the influence of the heart rate on pulmonary peak flow velocity in conscious Racing Pigeons (Columba livia $\mathrm{f}$. domestica). Each point represents the peak flow velocities depending on the heart rate. The solid line estimates the average peak flow velocity at each heart rate.

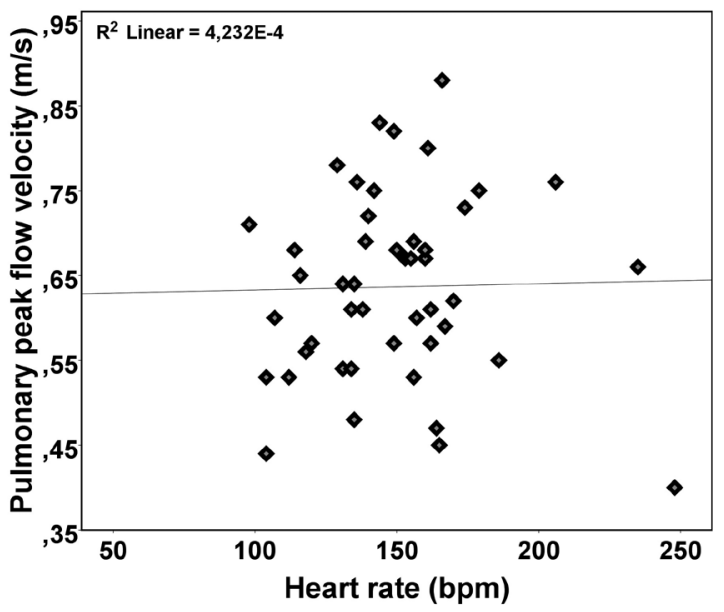

Fig. 7. Scatter diagram for the influence of the heart rate on pulmonary peak flow velocity in anaesthetized Racing Pigeons with isoflurane (Columba livia $\mathrm{f}$. domestica). Each point represents the peak flow velocities depending on the heart rate. The solid line estimates the average peak flow velocity at each heart rate.

similar to the described velocities in the literature for other bird species throughout anesthesia, for example, the African Grey Parrot: mean $0.89 \mathrm{~m} / \mathrm{s}$ or Amazon Parrot: mean $0.83 \mathrm{~m} / \mathrm{s}$ (Pees et al., 2006; Pees and Krautwald-Junghanns, 2009). The detected lower peak flow velocities in the PA compared with the AO are also described in mammals (Kirberger et al., 1992a,b; Boon, 2006). Comparative data of blood flow velocities in the PA of other bird species are not available in international publications. The anatomical characteristics of birds complicate an examination of the PA and the visualization of this heart vessel is only described in a 
few cases (Carrani et al., 2003; Pees et al., 2006; Pees and Krautwald-Junghanns, 2009). In our study, the PA could be visualized only in 40 out of 43 examined Racing Pigeons an in some cases a measurement was only possible in the right ventricular outflow tract and not in the valvular region. Investigations into blood flow velocities in dogs show that the velocities increase continuously from the outflow tract to the valvular region up to the artery in the left and right heart (Kirberger et al., 1992a,b). However, in the present study, the mistake in the echocardiographic evaluation in conscious and anesthetized pigeons was the same. The observed different aortic and pulmonary flow spectra and the shorter aortic ejection time in our study of Racing Pigeons are well described in humans and small mammals (Kirberger et al., 1992a,b; Boon, 2006). These typical different flow spectra have their origins in the lower vascular resistance in the pulmonary circulation compared with that in the body circulation, which is also described in birds (West et al., 2007). The significantly positive correlation of the weight/sternal length and the AT of pulmonary flow pattern could be also a sign of a higher vascular resistance in larger animals. The influence of an isoflurane narcosis on the flow pattern is mainly seen in a prolonged aortic and pulmonary ejection time, comparable to small mammals (Stypmann et al., 2007). Surprisingly, the anesthesia with isoflurane also had an effect on the pulmonary flow spectrum and led to balanced acceleration and deceleration times (Table 4). A possible explanation for this observation could be a changed blood pressure and a changed vascular resistance in the pulmonary circulation during anesthesia. An imbalance between the left and right heart can also lead to an increased right heart afterload during anesthesia, for example, caused by a left atrioventricular insufficiency induced by isoflurane.

First and second atrioventricular blocks are well described in the electrocardiographic examination of pigeons and other birds (Lumeij and Stockhof, 1985; Lumeji and Ritchie, 1994; Rüther, 1998). In horses, this phenomenon is considered a normal adaptation to prolonged training (Kroneman, 1965). In birds, a first or second atrioventricular block could also be an adaptation to a high-flight performance. The influence of anesthesia with isoflurane is significant and is also described in electrocardiographic examinations of birds in the literature (Lumeij and Ritchie, 1994; Murcia et al., 2005). An inhibition of $\mathrm{Na}^{+}-\mathrm{Ca}^{2+}$ exchange of cardiac cells could probably be an explanation (Sousa et al., 2008).

In the present study, in awake birds a positive correlation between peak flow velocities and heart rate could only be found in the pulmonary artery; there was no significant influence on aortic blood flow in the range of 118 to $330 \mathrm{bpm}$. It could be assumed that in a study with higher heart rates and more animals a correlation can be statistically shown. However, these results indicate that the higher blood pressure in the body circulation led to a more conserved aortic blood flow velocity. The lower pressure and vascular resistance in the pulmonary circulation allowed a fast change to higher blood flow velocities. There was a negative correlation between the heart rates and aortic peak flow velocities during isoflurane anesthesia. These results indicate that higher heart rates in anesthesia could be compensatory to a reduced blood pressure and vascular resistance (Touzot-Jourde et al., 2005; Botman et al., 2016). The results also show that the reduction of blood flow velocity under anesthesia is not simply caused by heart rate reduction (Straub et al., 2003).

\section{Conclusions}

The significant influence of an anesthesia with isoflurane on aortic and pulmonary peak flow velocities as well as flow pattern should be considered in the evaluation of the avian heart. The results indicate the necessity for establishing normal heart values in conscious and anaesthetized individuals. The significant influence of the heart rate on the systolic blood flow, especially of the pulmonary artery in awake birds should be borne in mind, especially during the examination of stressed conscious birds. The negative correlation of the heart rate and the peak flow velocity of anaesthetized Racing Pigeons with isoflurane confirmed the frequency of the heart beats as an important parameter in surveillance of anesthesia.

\section{Acknowledgments}

The authors would like to acknowledge the pigeon breeders for participating in this study and F. SherwoodBrock for critical revision of the manuscript.

\section{Conflict of interest}

None of the authors has any financial or personal relationships that could inappropriately influence or bias the content of the paper. This research did not receive any specific grant from funding agencies in the public, commercial, or not-for-profit sectors. The authors declare that there is no conflict of interest.

\section{References}

Boon,J.A.2006. Manual of veterinary echocardiography, $1^{\text {st }}$ ed. Oxford, UK: Blackwell Publishing.

Botman, J., Dugdale, A., Gabriel, F. and Vandeweerd, J.M. 2016. Cardiorespiratory parameters in the awake pigeon and during anaesthesia with isoflurane. Vet. Anaesth. Analg. 43, 63-71.

Boskovic, M., Krautwald-Junghanns, M-E., Failing, K. and Schneider, M. 1999. Möglichkeiten und Grenzen echokardiographischer Untersuchungen bei Tag- und Nachtgreifvögeln (Accipitriformes, Falconiformes, Strigiformes). Tierarztl. Prax. 27, 334-341.

Carrani, F., Gelli, D., Salvadori, M. and Aloisi, M. 2003. A preliminary echocardiographic initial approach to diastolic and systolic function in medium and large 
parrots. In the Proceedings of the 7th European Association of Avian Veterinarians, Puerto de la Cruz, Teneriffa, Spain, 22nd-26th April 2003, pp: 145-149.

Chaves, A.A., Weinstein, D.M. and Bauer, J.A. 2001. Noninvasive echocardiographic studies in mice influence of anesthetic regimen. Life Sci. 69, 213-222.

Deryck, Y.L.J., Brimioulle, S., Maggiorini, M., de Canniere, D. and Naeije, R. 1996. Systemic vascular effects of isoflurane versus propofol anesthesia in dogs. Anesth. Analg. 83, 958-964.

Eger, El. II. 1984. The pharmacology of isoflurane. Br. J. Anaesth. 56, 71-99.

Fudge, A.M. 2000. Laboratory medicine avian and exotic pets. Philadelphia, PA: W.B. Saunders Company.

Fox, P.R., Bond, B.R. and Peterson, M.E. 1985. Echocardiographic reference values in healthy cats sedated with ketamine hydrochlorid. Am. J. Vet. Res. 46, 1479-1484.

Kawasaki, T., Hoka, S., Okamoto, H., Okuyama, T. and Takahashi, S. 1994. The difference of isoflurane and Halothane in ventriculoarterial coupling in dogs. Anesth. Analg. 79, 681-686.

Kiatchoosakun, S., Kikpatrick, D. and Hoit, B.D. 2001. Effects of tribromethanol anesthesia on echocardiographic assessment of left ventricular function in mice. Comp. Med. 51, 26-29.

Kirberger, R.M., Bland-van den Berg, P. and Darazs, B. 1992a. Doppler echocardiography in the normal dog: Part I Velocity findings and flow patterns. Vet. Radiol. Ultrasound 33, 370-379.

Kirberger, R.M., Bland-van den Berg, P. and Grimbeek, R.J. 1992b. Doppler echocardiography in the normal dog: part II factors influencing blood flow velocities and a comparison between left and right heart blood flow. Vet. Radiol. Ultrasound 33, 380-386.

Klide, A.M. 1976. Cardiopulmonary effects of enflurane and isoflurane in the dog. Am. J. Vet. Res. 37, 127-131.

Korbel, R., Milovanovic, A. and Erhardt, W. 1993. Aerosacculare perfusion with isoflurane-an anaesthetic procedure for head surgery in birds. In the Proceedings of the 1993 European Conference of the Association of Avian Veterinarians, 3rd-6th March, Utrecht, Netherlands, pp: 9-42.

Korbel, R. 1998. Vergleichende Untersuchungen zur Inhalationsan€asthesie mit Isofluran (Forene) und Sevofluran (SEVOrane) bei Haustauben (Columba livia Gmel., 1789, var. domestica) und Vorstellung eines Referenz-Narkoseprotokolls für Vögel. Tierärztl. Prax. 26(K), 211-223.

Kroneman, J. 1965. The electrocardiogram of the trained horse. Doctoral thesis, University of Utrecht, Netherlands.

Lumeij, J.T. and Ritchie, B.W. 1994. Cardiology. In Avian Medicine, Principles and Application. Eds.,
Ritchie, B.W., Harrison, G.J. and Harrison, L.R.. Brentwood, TN: HBD Int'1 Inc., pp: 694-722.

Lumeij, J.T. and Stokhof, A.A. 1985. Electrocardiogram of the Racing Pigeon (Columba livia forma domestica). Res. Vet. Sci. 38, 275-278.

Marano, G., Formigari, R., Grigoni, M. and Vergari, A. 1997. Effect of isoflurane versus halothan on myocardial contractility in rabbits: assessment with transthoracic two-dimensional echocardiography. Lab. Anim. 31, 144-150.

Murray, D.J., Vandewalker, G., Matherne, G.P. and Mahoney, L.T. 1987. Pulsed-Doppler and twodimensional echocardiography: comparison of halothane and isoflurane on cardiac function in infants and small children. Anesthesiology 67, 211-217.

Murcia, L.M.M., Bernal, L.J., Montes, A.M. and Ayala, I. 2005. The normal electrocardiogram of the unanaesthetized competition 'Spanish Pouler' pigeon (Columba livia gutturosa). J. Vet. Med. A. Physiol. Pathol. Clin. Med. 52, 347-349.

Pagel, P.S., Kampine, J.P., Schmeling, W.T. and Warltier, D.C. 1991. Influence of volatile anesthetics on myocardial contractility in viva: desflurane versus isoflurane. Anesthesiology 74, 900-907.

Pees, M. 2001. Echokardiographische Untersuchungen bei Psittaciformes unter besonderer Berücksichtigung des Kongo-Graupapageis (Psittacus erithacus arithacus). Doctoral thesis, University of Leipzig, Germany.

Pees, M., Straub, J. and Krautwald-Junghanns, M-E. 2004. Echocardiographic examinations of 60 African grey parrots and 30 other psittacine birds. Vet. Rec. 155, 73-76.

Pees, M., Krautwald-Junghanns, M.-E. and Straub, J. 2006. Evaluation and treating the cardio-vascular system. In Clinical Avian Medicine. Eds., Harrison, G.J. and $\mathrm{T}$ Lightfoot. Palm Beach, FL: Spix Publishing, pp: 379-394.

Pees, M. and Krautwald-Junghanns, M-E. 2009. Cardiovascular physiology and diseases of pet birds. Vet. Clin. North Am. Exot. Anim. Pract. 12, 81-97.

Plante, E., Lachanche, D., Roussel, E., Drolet, M.C., Arsenault, M. and Couet, J. 2006. Impact of Anesthesia on echocardiographic evaluation of systolic and diastolic function in rats. J. Am. Soc. Echocardiogr. 19, 1520-1525.

Riedel, U. 1995. Die Ultrachalluntersuchung des Vogels am Beispiel der Brieftaube (Columba livia forma domestica) mit Hilfe der Schnittbildechokardiographie. Doctoral thesis, Justus-Liebig-Universität Gießen, Gießen, Germany.

Roth, D.M., Swaney, J.S., Dalton, N.D., Gilpin, E.A. and Ross, JR. 2002. Impact of anesthesia on cardiac function during echocardiography in mice. Am. J. Physiol. Heart Circ. Physiol. 282, H2134-H2140. 
Rüther, P. 1998. Untersuchungen zur tageszeitabhängigen Rhythmik der Ruheherzfrequenz und ausgewählter Arrhythmien bei der Brieftaube (Columba livia f. domestica). $\mathrm{PhD}$ thesis, Free University of Berlin, Berlin, Germany.

Schulz, M. 1995. Morphologische und funktionelle Messungen am Herzen von Brieftauben (Columba livia forma domestica) mit Hilfe der Schnittbildechokardiographie. Doctoral thesis, Justus-Liebig-Universität Gießen, Germany.

Sousa, M.G., Carareto, R., De-Nardi, A.B., Brito, F.L.C., Nunes, N. and Camacho, A. 2008. Effects of isoflurane on echocardiographic parameters in healthy dogs. Vet. Anaesth. Analg. 35, 185-190.

Stein, A.B., Tiwari, S., Thomas, P., Hunt, G., Levent, C., Stoddard, M.F., Tang, X.-L., Bolli, R. and Wawn, B. 2007. Effects of anesthesia on ecocardographic essessment of left ventricular structure and function in rats. Basic Res. Cardiol. 102, 28-41.

Steffey, E.P. and Howland, D. Jr. 1978. Isoflurane potency in dog and cat. Am. J. Vet. Res. 38, 18331836.

Straub, J., Forbes, N.A., Thielebein, J., Pees, M. and Krautwald-Junghanns, M-E. 2003. The effects of isoflurane anaesthesia on some Doppler-derived cardiac parameters in the Common Buzzard (Buteo buteo). Vet. J. 166, 273-276.

Straub, J., Pees, M., Schumacher, J., Gompf, R.E., Basade, H. and Kautwald-Junghanns, M-E. 2001. Dopplerechocardiography in birds. In the Poceedings of the 6th Main Conference of the European Association of Avian Veterinarians, 8th10th March, Munich, Germany, pp: 92-94.
Stypmann, J., Engelen, M.A., Breithardt, A.-K., Milberg, P., Rothenburger, M., Breithardt, O.A., Breithardt, G., Eckardt, L. and Poulsen Nautrup, C. 2007. Doppler echocardiography and tissue Doppler imaging in the healthy rabbit: differences of cardiac function during awake and anaesthetized examination. Int. J. Cardiol. 115, 164-170.

Touzot-Jourde, G., Hernandez-Divers, S.J. and Trim, C.M. 2005. Cardiopulmonary effects of controlled versus spontaneous ventilation in pigeons anesthetized for coelioscopy. J. Am. Vet. Med. Assoc. 227, 1424-1428.

Vastenberg, M.H.A.C., Boroffka, S.A.E.B. and Schoemaker, N.J. 2004. Echocardiographic measurements in clinically healthy ferrets anesthetized with isoflurane. Vet. Radiol. Ultrasound 45, 228-232.

West, J.B., Watson, R.R. and Fu, Z. 2007. Major differences in the pulmonary circulation between birds and mammals. Respir. Physiol. Neurobiol. 157, 382-390.

Yamanaka, T., Oku, K., Koyama, H. and Mizuno, Y. 2001. Time-related changes of the cardiovaskulare system during maintenance anesthesia with sevoflurane and isoflurane in horses. J. Vet. Med. Sci. 63, 527-532.

Yang, X., Liu, Y., Rhaleb, N., Kurihara, N., Kim, H.E. and Carretero, O.A. 1999. Echocardiographic assessment of cardiac function in conscious and anesthetized mice. Am. J. Physiol. Heart Circ. Physiol. 277, H1967-H1974. 